\title{
EXPERIMENTAL INVESTIGATION OF THE TENSILE STRENGTH OF THE HYBRID FIBRES- REINFORCED POLYMER (FRP)
}

\author{
Mohaseb Ahmed Abozied* \\ Civil Engineering Department, Luxor Higher Institute of Engineering \& Technology, \\ Luxor 85834, Egypt \\ Mamdouh Sayed Abdelbaqi \\ Civil Engineering Department, Luxor Higher Institute of Engineering \& Technology, \\ Luxor 85834, Egypt \\ Mohamed Ahmed Saifeldeen \\ Civil Engineering Department, Aswan University, Egypt \\ Hossameldeen Mohamed \\ Civil Engineering Department, Aswan University, Egypt \\ Omar Ahmed Farghal \\ Civil Engineering Department, Assiut University, Egypt \\ Abd El Rahman Megahid Ahmed \\ Civil Engineering Department, Assiut University, Egypt \\ *Corresponding Author Email: eng.mohaseb201509@gmail.com
}

\begin{abstract}
Fibre-reinforced polymer (FRP) has been widely used for strengthening and repairing of concrete structures which can enhance the flexural strength, fatigue strength and the durability of the concrete structures. Among other types of FRP, Glass FRP (GFRP) is seen as an affordable material compared to carbon or aramid fibres. However, the low modulus of elasticity of GFRP obstructs their widespread use in construction applications. In order to enhance the mechanical properties of GFRP, this study incorporates GFRP with carbon fibre-reinforced polymer (CFRP) in a single polymer matrix. Two approaches were followed to fabricate hybrid bars with different characteristics. The fabricated hybrid bars were tested under axial tensile loading test. The obtained results show that the new hybrid bars have higher tensile strength compared by the conventional GFRP.
\end{abstract}

Keywords: Tensile test; Glass fibre-reinforced polymers GFRP; Hybridization, Tensile strength. 
Mohaseb Ahmed Abozied, Mamdouh Sayed Abdelbaqi, Mohamed Ahmed Saifeldeen, Hossameldeen Mohamed, Omar Ahmed Farghal, Abd El Rahman Megahid Ahmed

Cite this Article: Mohaseb Ahmed Abozied, Mamdouh Sayed Abdelbaqi, Mohamed Ahmed Saifeldeen, Hossameldeen Mohamed, Omar Ahmed Farghal, Abd El Rahman Megahid Ahmed, Experimental Investigation of the Tensile Strength of the Hybrid Fibres-Reinforced Polymer (FRP). International Journal of Civil Engineering and Technology, 11(5), 2020, pp. 28-39.

https://iaeme.com/Home/issue/IJCIET?Volume=11\&Issue=5

\section{INTRODUCTION}

The erosion of steel bar is one of the main causes for the shortening of the service life of reinforced concrete (RC) structures. Consequently, this phenomenon is considered one of the most cost-demanding issues in term of maintenance during the service life. To overcome this problem in RC structures, Fibre Reinforced Polymers (FRP) is proposed as an alternative material to replace or added to the rebars in construction [1]. Glass and carbon are commonly used fibre materials. Carbon fibre exhibits higher tensile strength and some cases, more elastic modulus than steel which are advantageous features of using carbon fibre in a structural point of view but in some cases it is not economical, since its price is almost ten times higher than glass fibre which can be more beneficial material in initial cost. However, low modulus of elasticity is the main limitation in case of using glass fibres, which approximately less than a quarter of steel modulus. This leads to excessive deflection when FRP rebar were used as the reinforcement for flexural members. For this reason, the concept of "hybridization" is needed for the FRP rebar to overcome their Shortcomings [7].

In 1994, Jones and DiBenedetto [8] carried out experiments on hybrid composite specimens constituted by carbon/carbon, glass/glass, aramid/carbon, and glass/carbon fibres. This study revealed that pseudo-ductile behaviour occurred to the specimen in which low elongation fibres was well-distributed in small quantities. It worth noticing that the latter conclusion was recognized before by Kretsis [9]. Also Kretsis reported that the effect of hybridization on tensile properties of FRP rods was obtained by comparing the results of tensile test for the hybrid rods with those of the non-hybrid rods is more distinctive as the ratio and the concentration of low elongation fibres gets smaller. In 1976, Phillips [10] demonstrated that the fibres exhibit the pseudo-ductile behaviour and can sustain the additional loads in case of ductile behaviour. Based on the experimental results performed on the pultruded hybrid rods with different volume fraction and the arrangements of fibres (glass, aramid, carbon), Bakis et al. [2] reported that the specimens showed a pseudo-ductile behaviour with progressive failure regardless of the quantity of carbon fibres or of the type of high elongation fibres. Also, it has been noticed that a good pseudo-ductile behaviour was obtained for the specimen with well-distributed carbon fibres. Three year later, Yujin et al. [11] performed tensile tests on hybrid rods with carbon and glass fibres. Test results revealed that hybrid rods with carbon fibres showed a distinct pseudo-ductile behaviour where several subsequent stress peaks are repeated. Also, it has observed that, for specimens with carbon fibres concentrated in the core, a secondary failure occurred at stress larger than the maximum stress developed at the initial failure. FRP rods consisting of glass or carbon fibres were also fabricated for comparison.

In this context, in this study, hybrid bars were used to improve tensile performance and flexibility coefficient. The principle of the hybridization is to make balance between the mechanical characteristics of the used fibres and the production cost. In this context, the carbon fibres were incorporated with fibres glass to overcome non-economic and low modulus of elasticity of carbon and glass fibres, respectively. This study presents an experimental investigation on the tensile properties of the hybrid and non-hybrid FRP rods. The tested specimens were prepared at the laboratory. The effect of hybridization on tensile 
properties of FRP rods was obtained by comparing the results of tensile test for the hybrid rods with those of the non-hybrid rods

\section{EXPERIMENTAL WORK}

\subsection{FRP Reinforcement Bars Manufacturing and Testing}

GFRP and CFRP bars were manufactured locally at laboratory. The moulds were prepared to produce bars with diameter of $8,10,12$ and $16 \mathrm{~mm}$. Two fabrication methods were used, the first one by heating the bars during the manufacturing process while the other one is manufacturing the bars without heating. The manufacturing steps are shown in figures ( 1 and 2). This study considers glass and carbon fibres in order to investigate a hybrid effect according to the mixing of different types of fibres. Three types of FRP rod samples were fabricated as summarized in Table 1. Types G, and C stands for GFRP and CFRP without hybridization, while type CG stands for hybrid FRP bar of GFRP incorporated with CFRP. All types of samples are compared with the conventional steel (type $S$ ).

Table 1 Material type and bar diameter of the tested specimen

\begin{tabular}{|c|c|c|c|}
\hline Material & Actual Bar diameter (mm) & Type of bar & Notes \\
\hline \multirow{4}{*}{ Steel bar } & 8.1 & \multirow[t]{4}{*}{$\mathrm{C}_{\mathrm{s}}$} & \multirow{4}{*}{------------- } \\
\hline & 10.2 & & \\
\hline & 11.9 & & \\
\hline & 16.1 & & \\
\hline \multirow{4}{*}{ GFRP } & 7.9 & \multirow{4}{*}{ G } & \multirow{4}{*}{------- } \\
\hline & 10.1 & & \\
\hline & 12.1 & & \\
\hline & 15.9 & & \\
\hline \multirow{4}{*}{ CFRP } & 8.1 & \multirow{4}{*}{$\mathrm{C}$} & \multirow{4}{*}{------- } \\
\hline & 9.9 & & \\
\hline & 12 & & \\
\hline & 16.1 & & \\
\hline \multirow{4}{*}{$\begin{array}{l}\text { Hybrid } \\
\text { (GFRP+CFRP) }\end{array}$} & 8 & \multirow{4}{*}{$\mathrm{GC}$} & \multirow{4}{*}{$50 \% \mathrm{CFRP}+50 \% \mathrm{GFRP}$} \\
\hline & 10.2 & & \\
\hline & 12.1 & & \\
\hline & 16.1 & & \\
\hline \multirow{4}{*}{$\begin{array}{l}\text { Hybrid (GFRP+ } \\
\text { CFRP) }\end{array}$} & \multirow{4}{*}{8.1} & \multirow{4}{*}{ GC } & $25 \% \mathrm{CFRP}+75 \% \mathrm{GFRP}$ \\
\hline & & & $35 \%$ CFRP $+65 \%$ GFRP \\
\hline & & & $65 \% \mathrm{CFRP}+35 \%$ GFRP \\
\hline & & & $75 \%$ CFRP $+25 \%$ GFRP \\
\hline
\end{tabular}

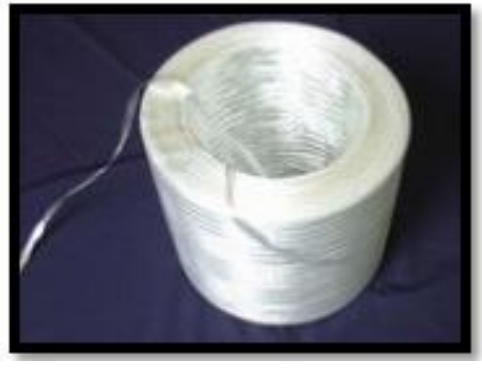

(1)

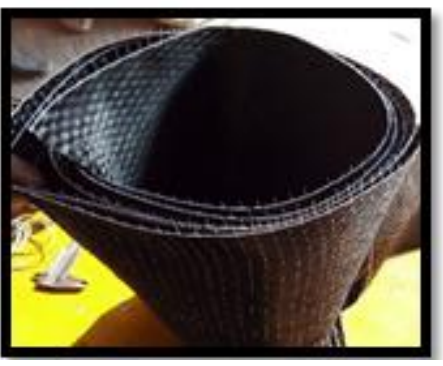

(2)

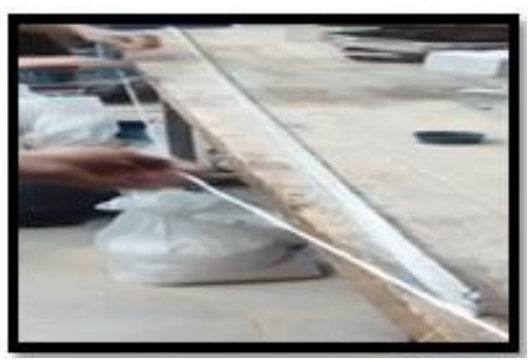

(3) 
Mohaseb Ahmed Abozied, Mamdouh Sayed Abdelbaqi, Mohamed Ahmed Saifeldeen, Hossameldeen Mohamed, Omar Ahmed Farghal, Abd El Rahman Megahid Ahmed

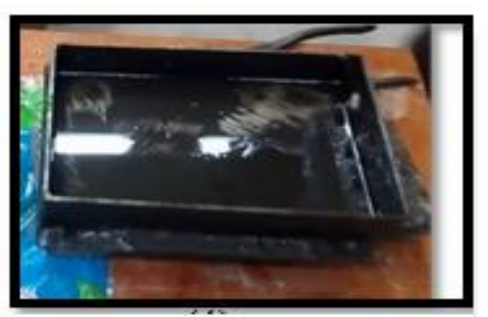

(4)

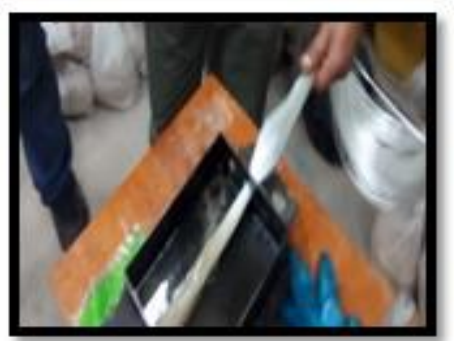

(7)

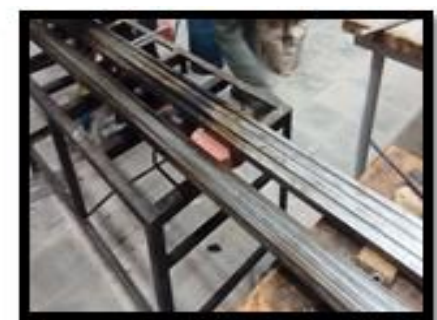

(5)

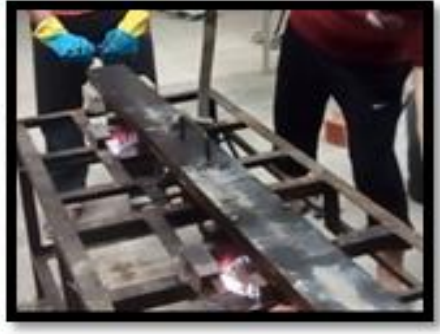

(8)

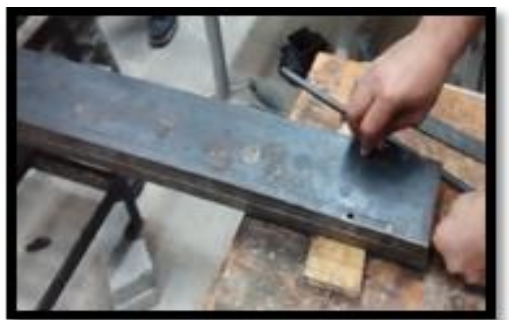

(6)

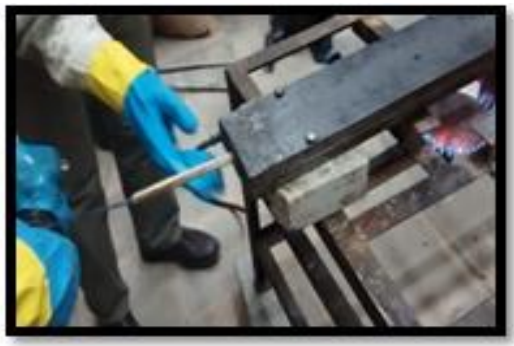

(9)

Figure 1 Steps of manufacturing FRP bars by heating

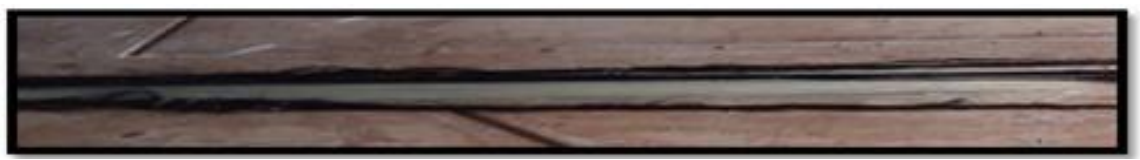

(1)

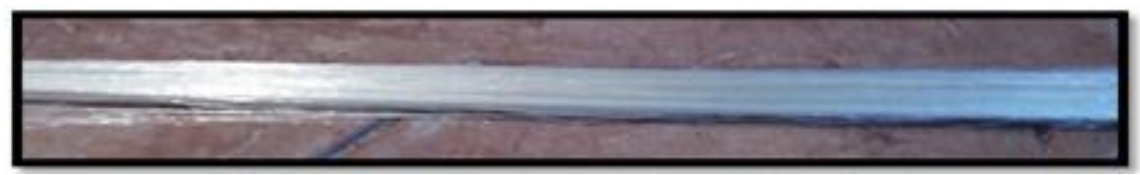

(2)

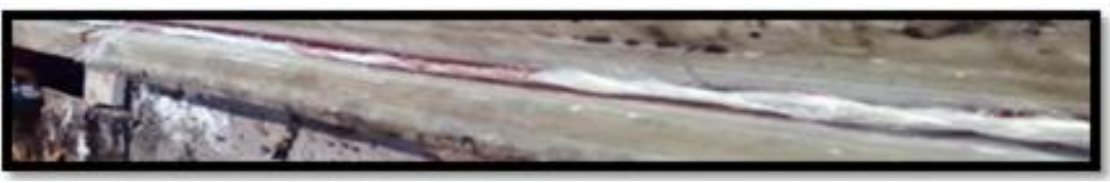

(3)

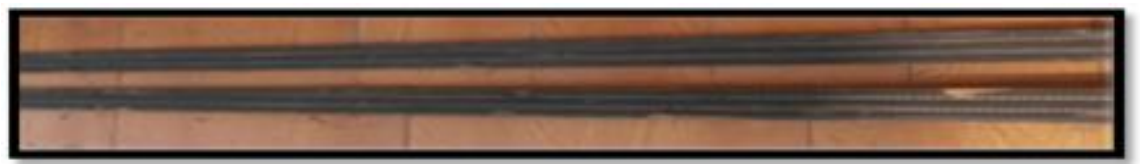

(4)

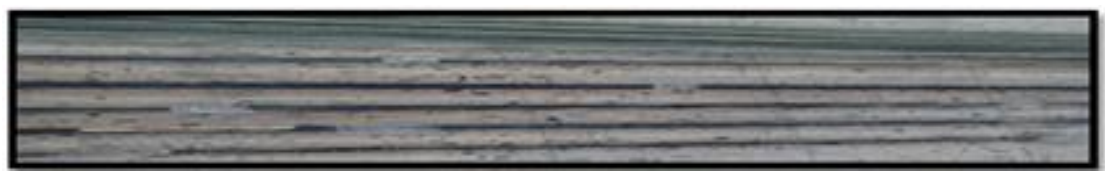

(5)

Figure 2 Steps of manufacturing FRP bars without heating 


\subsection{Preparation of Samples for Tensile Test}

A set of 50 specimens with $90 \mathrm{~cm}$ were prepared and tested under axial tensile loading according to ECP 203[5]. Two tubes of $300 \mathrm{~mm}$ length were attached to the rod using injected epoxy resin to provide bond between the samples and to prevent any slippage during testing. The ends of each sample bar were enclosed with plastic Teflon rings. In order to monitor the strain for the tested rods, one strain gauge of $10 \mathrm{~mm}$ length was used and attached to the centre of the specimen as shown in fig 3 .
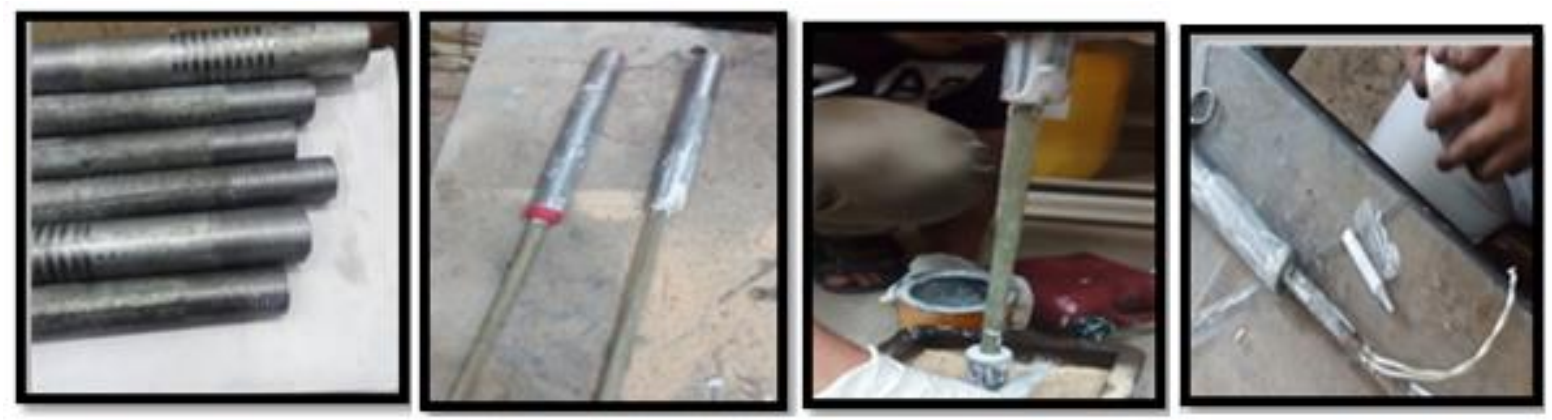

Figure 3 Preparation of Samples for tensile test

\subsection{Tensile Test procedure}

All tests were conducted using a tensile testing machine shown in fig (4), according to ECP $208[1,6]$. The specimen has set into the testing machine and gripped by the jaws, ensuring that the full $900 \mathrm{~mm}$ jaw length was engaged. Load has been applied gradually until the bar was loaded to 20 and $50 \%$ of the predicted ultimate load. LVDT was used to measure elongation. The testing continued until failure of the bar. The applied load in (KN), elongation in $(\mathrm{mm})$ and strain were recorded by a data logger system which connected to the specimen before the load applicaiton.
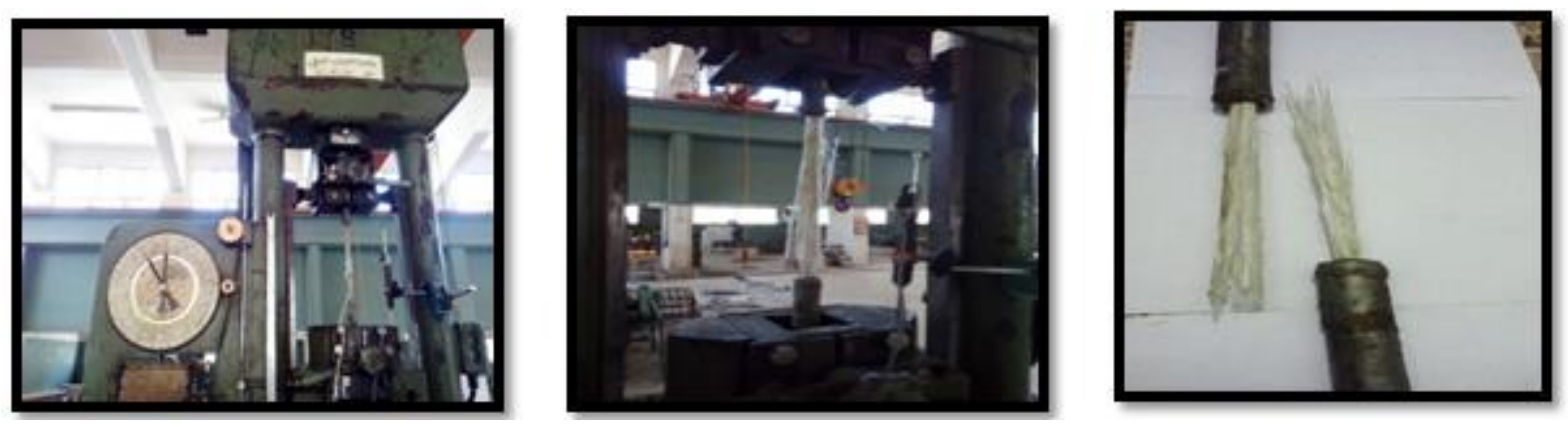

Figure 4 Test setup and fracture types for different specimens

\section{TEST RESULTS AND DISCUSSION}

The tensile strength of the specimen was calculated. As well as the elastic modulus of the FRP and hybrid rod was calculated using the following equation as recommended in the ECP 203 [5] and CSA S806-02 [4].

$$
\begin{aligned}
& E_{\text {rod }} \\
& =\frac{\left(p_{1}-p_{2}\right)}{\left(\varepsilon_{1}-\varepsilon_{2}\right) A_{\text {rod }}}
\end{aligned}
$$

where, $p \_1$ and p_2 are the applied loads corresponding to $25 \%$ and $50 \%$ of the expected ultimate load respectively, and $\varepsilon_{-}$land $\varepsilon_{-} 2$ are the corresponding measured strains. Table 2 
Mohaseb Ahmed Abozied, Mamdouh Sayed Abdelbaqi, Mohamed Ahmed Saifeldeen,

Hossameldeen Mohamed, Omar Ahmed Farghal, Abd El Rahman Megahid Ahmed

shows the tensile strength and elastic modulus for different specimens. Table 3 summarize the results of tensile tests for the tested bars. Three average values of ultimate tensile test and strains were calculated and presented in Table 3. Figure 5 shows the stress - strain relationship for different specimens.

Comparing to GFRP bar without hybridization (G) tensile strengths were increased to $24 \%$ in type (CG) Even though elastic modulus were increased 206\% in type (CG). Though the minimum tensile strength was $1240.6 \mathrm{MPa}$, this value is higher than tensile strength of general steel rebar. The elastic modulus of type (G C) can be applied to concrete structures exposed to aggressive environments effectively than GFRP without hybridization. Also, price of CFRP decrease to $42.5 \%$

Table 2 Relative tensile strength and elastic modulus for different specimens.

\begin{tabular}{|c|c|c|c|c|c|c|}
\hline Type & $\begin{array}{c}\text { Average (Yield } \\
\text { or ultimate } \\
\text { Tensile } \\
\text { strength) (Mpa) }\end{array}$ & $\begin{array}{c}\text { Improvement } \\
\text { s of strength } \\
(\%) \text { with } \\
\text { respect to } \\
\text { GFRP }\end{array}$ & $\begin{array}{c}\text { Elastic } \\
\text { modulus (Gpa) }\end{array}$ & $\begin{array}{c}\text { Improvements } \\
\text { of Elastic } \\
\text { modulus (\%) } \\
\text { with respect to } \\
\text { GFRP }\end{array}$ & $\begin{array}{c}\text { Cost for1m } \\
\text { (Egyptian } \\
\text { Pound) }\end{array}$ & $\begin{array}{c}\text { Improvements } \\
\text { of cost (\%) } \\
\text { with respect to } \\
\text { CFRP }\end{array}$ \\
\hline G & 1146.8 & 1 & 46 & 1 & 30 & 75 \\
\hline C & 1833.2 & 1.6 & 129.1 & 2.8 & 120 & 1 \\
\hline GC & 1427.7 & 1.24 & 95.2 & 2.06 & 70 & 42.5 \\
\hline
\end{tabular}

Table 3 Results of tensile tests for three average values of specimens.

\begin{tabular}{|c|c|c|c|c|c|}
\hline Type & Diameter (mm) & $\begin{array}{c}\text { Yield tensile } \\
\text { stress or proof } \\
\text { stress (MPa)) }\end{array}$ & $\begin{array}{l}\text { Ultimate tensile } \\
\text { strength (MPa)) }\end{array}$ & $\begin{array}{l}\text { Elastic modulus } \\
\text { GPa) }\end{array}$ & $\begin{array}{c}\text { Ultimate strain } \\
\%\end{array}$ \\
\hline \multirow{4}{*}{ Steel bar } & 7.9 & 248 & 355 & 200 & 2.96 \\
\hline & 9.90 & 368 & 667.6 & 210 & 3.2 \\
\hline & 12 & 463.4 & 681.3 & 210 & 4.2 \\
\hline & 15.9 & 470 & 687.5 & 210 & 4.51 \\
\hline \multirow{4}{*}{ GFRP bar } & 8.1 & -------- & 1240.6 & 47 & 2.64 \\
\hline & 10.1 & $\begin{array}{l}------- \\
-\end{array}$ & 1146.8 & 46 & 2.5 \\
\hline & 11.90 & -------- & 1072.67 & 44.2 & 2.43 \\
\hline & 16 & -------- & 1008.8 & 47 & 2.15 \\
\hline \multirow{4}{*}{ CFRP bar } & 7.99 & -------- & 1730 & 125.4 & 1.38 \\
\hline & 10.1 & $\begin{array}{l}------- \\
-1\end{array}$ & 1833.2 & 129.1 & 1.42 \\
\hline & 12 & -------- & 1916.9 & 123 & 1.56 \\
\hline & 16.1 & -------- & 1960.8 & 124.1 & 1.58 \\
\hline \multirow{4}{*}{$\begin{array}{c}\text { Hybrid } \\
\text { (GFRP+ } \\
\text { CFRP) bar }\end{array}$} & 8.1 & -------- & 1380.6 & 85.2 & 1.62 \\
\hline & 10.2 & -------- & 1427.7 & 95.2 & 1.5 \\
\hline & 12.1 & -------- & 1384.5 & 94.8 & 1.46 \\
\hline & 16.1 & -------- & 1470.8 & 88.1 & 1.67 \\
\hline \multirow{4}{*}{$\begin{array}{c}\text { Hybrid } \\
\text { (GFRP+ } \\
\text { CFRP) bar } \\
8.1 \mathrm{~mm}\end{array}$} & $25 \%$ CFRP+75\%GFRP & ----------- & 1293.6 & 87.2 & 1.48 \\
\hline & $35 \%$ CFRP+65\%GFRP & $\begin{array}{l}----------- \\
\end{array}$ & 1400.8 & 98.3 & 1.425 \\
\hline & $65 \%$ CFRP+35\%GFRP & ------------ & 1490.6 & 107 & 1.39 \\
\hline & 75\% CFRP+25\%GFRP & ------------ & 1610.3 & 116.43 & 1.38 \\
\hline
\end{tabular}



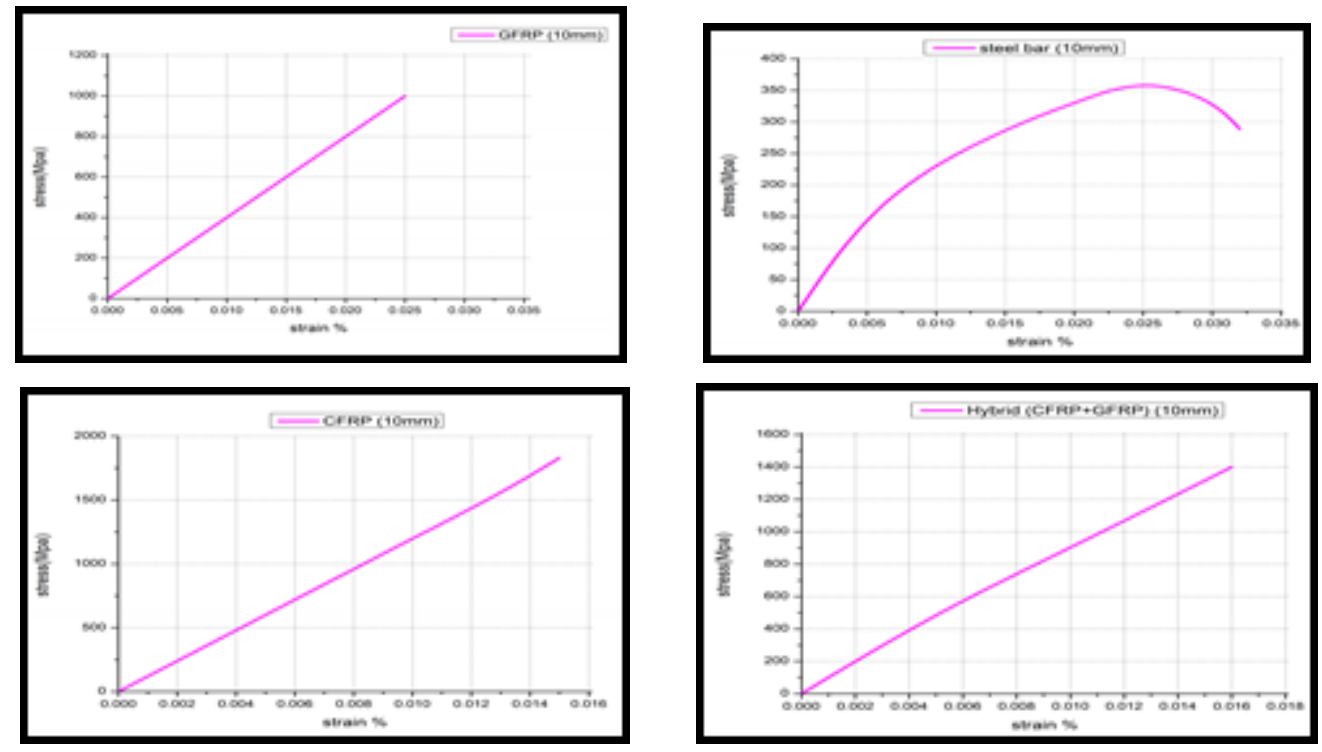

Figure 5 The stress - strain relationship for different specimens for 10mm diameter.

\section{PARAMETRIC STUDY}

The effect of the relevant parameters to the tensile strength of the hybrid bars are analysed in light of the obtained results. Next sections provide a systematic discussion for these parameters.

\subsection{Bar Surface}

The effect of the bar surface on tension test of FRP bars was very clear .In the case of ribbed bars the ultimate tensile strength was very high while in the sand coated bars the ultimate tensile strength was reduced by about $(10.5) \%$. and in the smooth bars the ultimate tensile strength decreased by about (16) \% for the same diameters.as shown in figures (6)
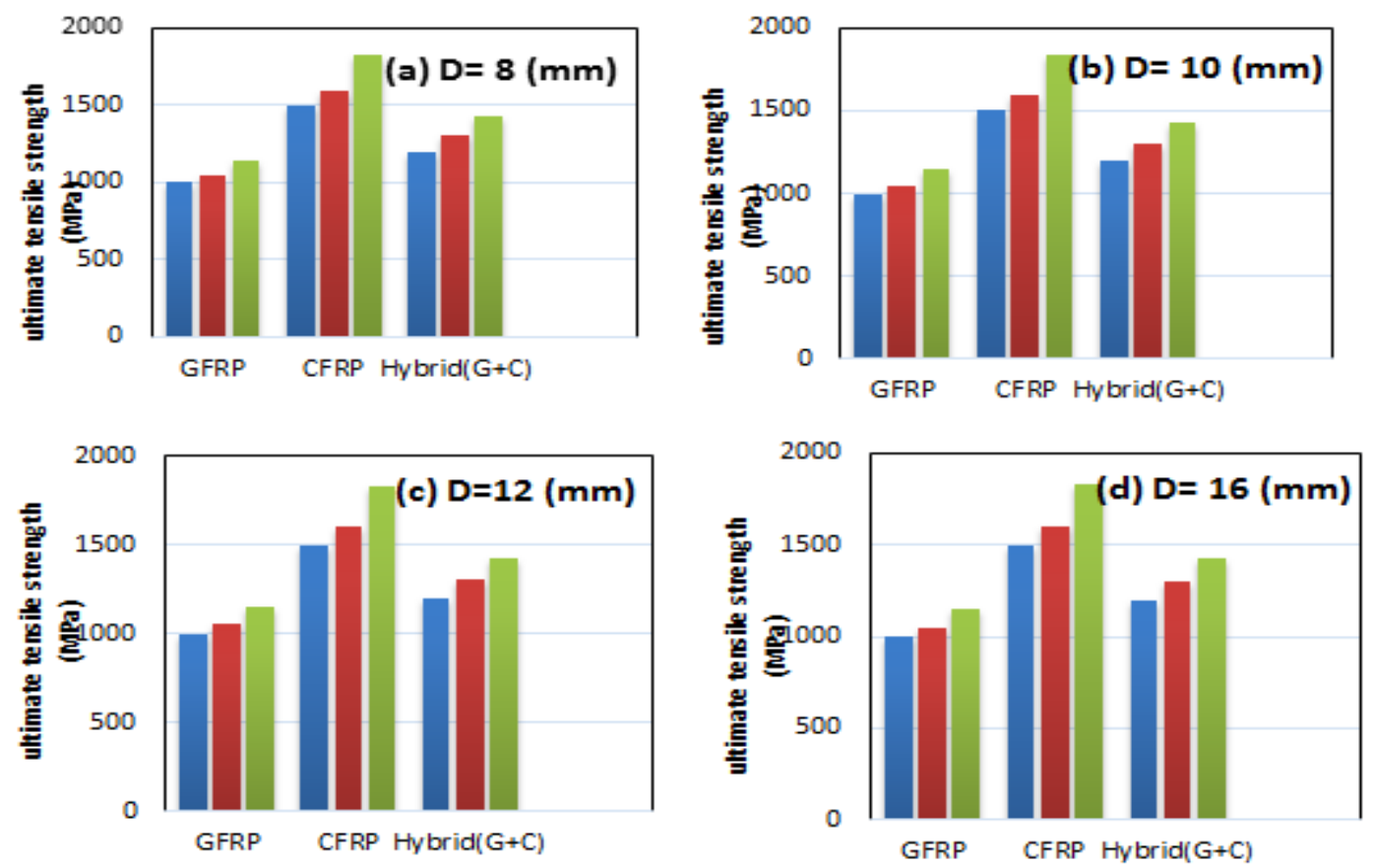

=Smooth $=$ Sand coated $2 \equiv$ Rbbed

Figure 6 Effect of the bar surface 


\subsection{Bar Diameter}

The effect of bar diameter was not constant in all types but it changed from one type to another .Mostly, the tensile values in non-hybrid bar and hybrid bar CFRP with GFRP are inversely proportional to the diameter. As shown in fig 7.

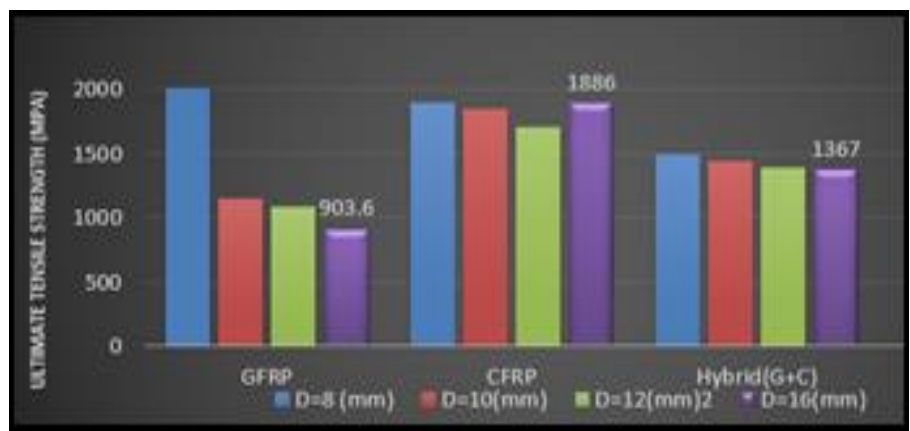

Figure 7 Effect of the bar diameter

\subsection{Embedded Length in Tube}

The effect of embedment length on the ultimate tensile strength was very clear in all samples. Where the higher of the embedment length leads to perfect bond and prevents any slippage of the bar during the tension test, see Fig (8) and fig (9).

\section{Embedment length in tube $=25 \mathrm{~cm}$}

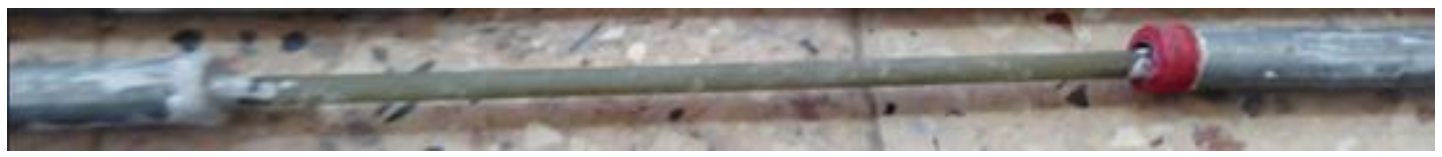

Embedment length in tube $=35 \mathrm{~cm}$

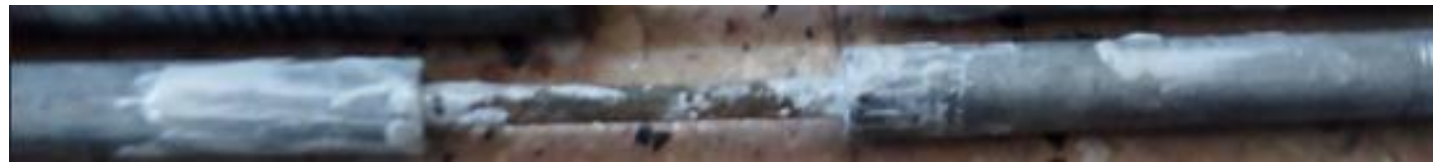

Embedment length in tube $=40 \mathrm{~cm}$

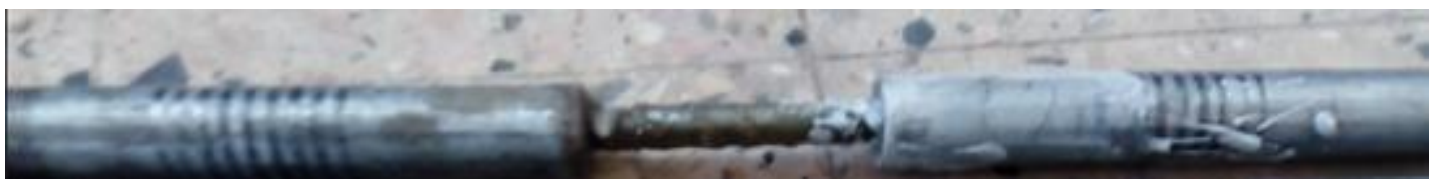

Figure 8 The Embedment length in tube 

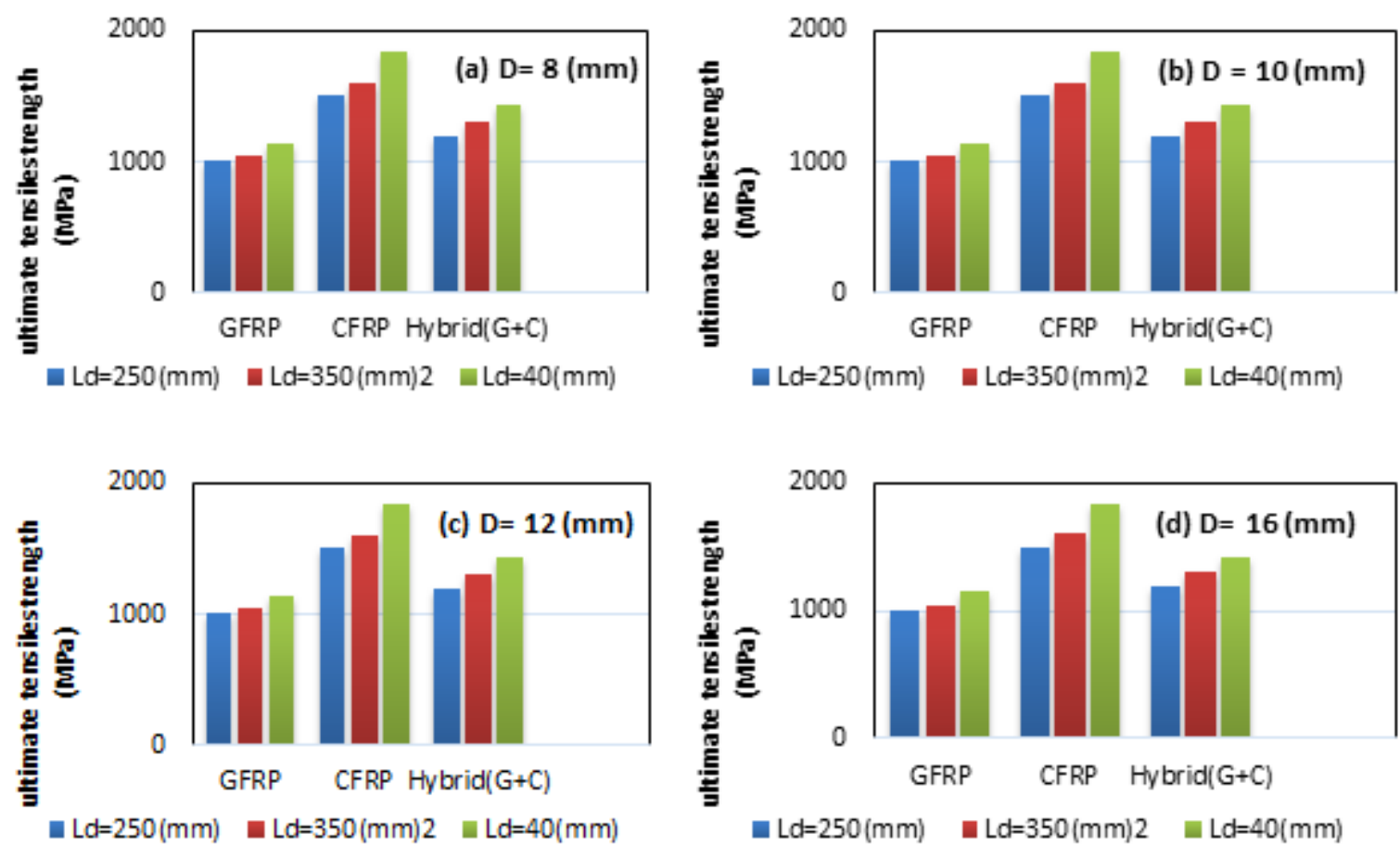

Figure 9 Effect of the Embedment length in tube

\subsection{Type of Adhesion Material}

Some of the tested samples fixed by Sikadure 30 had a sliding effect and the other samples were less in ultimate tensile strength than the tested samples fixed with kemaboxy 165.see Fig 10 .
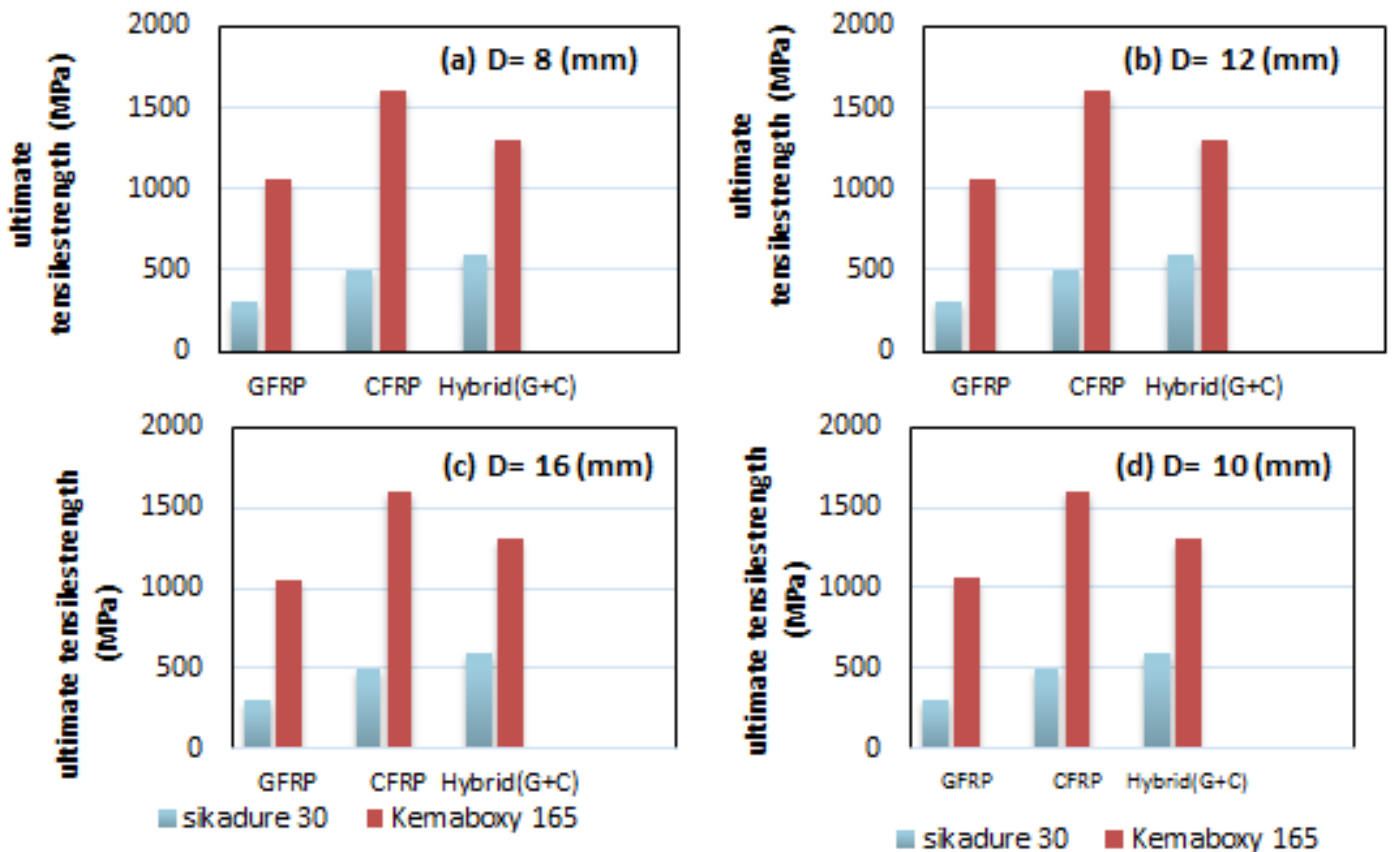

Figure 10 Effect of Type of adhesion material (Kemaboxy 165 and Sikadure 30) 


\subsection{Adhesion Hardening Period}

Samples tested after 10 days of manufacturing have exhibited a slippage during the test and gave a small value in ultimate tensile strength see Fig.11. However, Samples tested after 30 days of manufacturing did not slip during the test and gave a high ultimate tensile strength; see Fig (12)

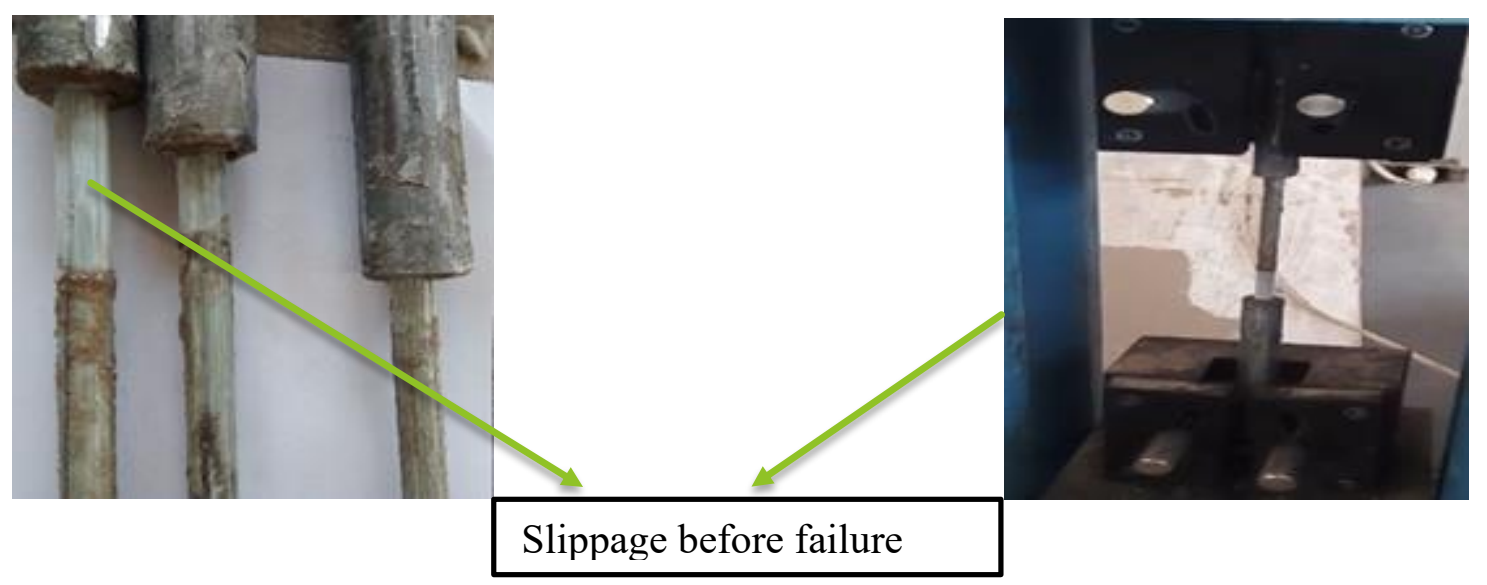

Figure 11 Shows slippage during the test.
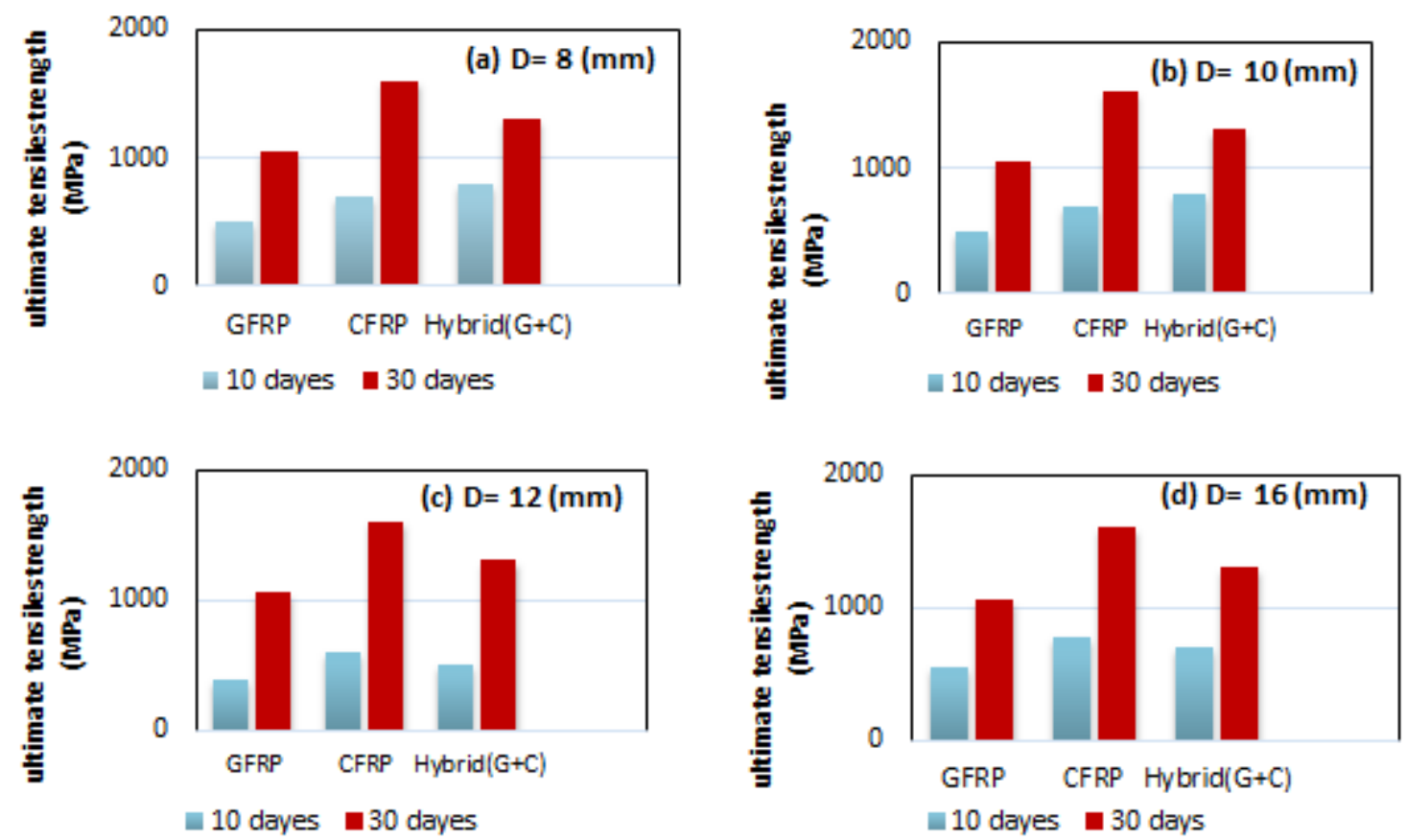

Figure 12 The of Effect the Period Time for adhesion (10 - 30) day

\subsection{Toughness}

It expresses the material's ability to absorb the mechanical energy until failure occurs and it is estimated from the total area under the stress and strain curve and measured in the stress units see fig 13.Moudulus of toughness was presented in fig 13. The experimental results in this study showed that the modulus of toughness in steel bar was lower than that for FRP bars and Reinforcement Ratio of FRP bars .This because the ultimate tensile strength of steel bar is lower than that ultimate tensile strength of FRP bars. 

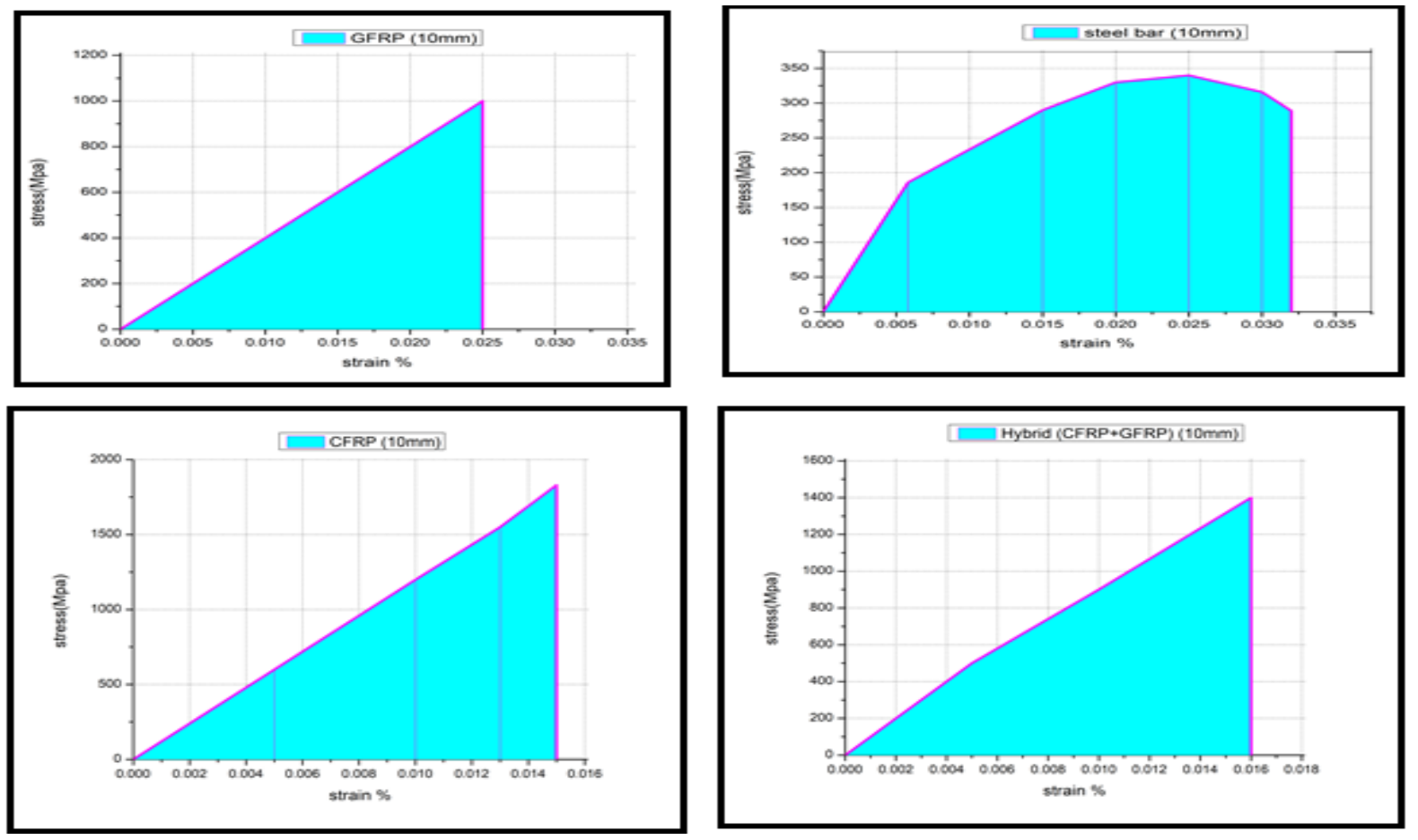

Figure 13 Determining the modulus of toughness of tested bar type.(10mm diameter)

\section{CONCLUSIONS}

In this study, prototypes of FRP hybrid bars with CFRP and GFRP bars were developed according to the diameter and proportion of CFRP bars:

- The ultimate tensile strength was increased by increasing the embedment length and the probability of slip is zero.

- The ultimate tensile strength has improved completely in case of the use ribbed barsThe use of kemaboxy 165 and treatment for one month gave clear results and reduced of probability of slipping during the test.

- Carbon hybridization has obtained a high elasticity coefficient at a low price. Where the coefficient of elasticity increased by $206 \%$, the tensile strength to $24 \%$ and the cost has fallen to $42.5 \%$. (According $10 \mathrm{~mm}$ diameter) increasing carbon ratio from $25 \%$ to $75 \%$ led to an improvement of $33 \%$ in elastic modules, $24 \%$ in Ultimate tensile strength $t$ reduced elongation to $7 \%$ According to the diameter used.

\section{REFERENCES}

[1] ASTM D 3916. In: Standard test method for tensile properties of pultruded glass-fibresreinforced plastic rods. 2002.

[2] Bakis CE, Nanni A, Terosky JA, Koehler SW. Self-monitoring, pseudo-ductile, hybrid FRP reinforcement rods for concrete applications. Compos Sci Technol 2001; 61(6):81523.

[3] Canadian Society of Civil Engineers. Advanced composites materials with application to bridges. In: Mufti A, Erki MA, Jaeger L, editors. Canada: Montreal; 1991.

[4] CSA S806-02. In: Test method for tensile properties of FRP reinforcement. Canadian Standard Association; 2002.

[5] Egyptian Code of Practice for Design and Construction of Reinforced Concrete Structures, (ECP203-2007), Housing and Building National Research Center, Giza, Egypt. 
Mohaseb Ahmed Abozied, Mamdouh Sayed Abdelbaqi, Mohamed Ahmed Saifeldeen, Hossameldeen Mohamed, Omar Ahmed Farghal, Abd El Rahman Megahid Ahmed

[6] Egyptian Code of Practice for Design and Construction for FRP Reinforced Concrete Structures, (ECP208-2005), Housing and Building National Research Center, Giza, Egypt.

[7] Y.J. You, Y.H. Park, H.Y. Kim, J.S. Park. (2007). Hybrid effect on tensile properties of FRP rods with various material compositions, Composite Structures. Vol. 80, No. 1, 117122.

[8] Jones KD, DiBenedetto AT. Fibres fracture in hybrid composite systems. Compos Sci Technol 1994; 51(1):53-62.

[9] Kretsis G. A review of the tensile, compressive, flexural and shear properties of hybrid fibre-reinforced plastics. Composites 1987;18(1): 13-23.

[10] Phillips LN. The hybrid effect - does it really exist? Composites 1976;7(1):7-8.

[11] Reinforcement rods for concrete applications. Compos Sci Technol 2001;61(6):815-23.

[12] Yujin L, Changsen S, Farhad A. Acoustic emission characterization of damage in hybrid fibres-reinforced polymer rods. J Compos Constr 2004; 8(1):70-8. 